\title{
Assessment of energy sustainability and development of companies based on cognitive modeling
}

\author{
Svetlana Drobyazko ${ }^{1 *}$, Tetiana Hilorme ${ }^{2}$, Valentyna Shevchenko ${ }^{3}$, Olena Yudina ${ }^{4}$ \\ ${ }^{1}$ Doctor of Economic Sciences, Professor, President of the European Academy of Sciences, 71-75 \\ Shelton Street Covent Garden, London, United Kingdom. \\ ${ }^{2}$ Oles Honchar Dnipro National University, Ukraine. \\ ${ }^{3}$ Alfred Nobel University, Ukraine. \\ ${ }^{4}$ Higher Educational Institution "Dnipro Humanities University", Ukraine.
}

\begin{abstract}
It is proved that innovations in the field of energy are a priority for sustainable development at all levels of the economy. The purpose of this work is to build a cognitive model of enterprise development based on energy saving. Cognitive-linguistic analysis has been used as the main method for forming a system of substantiation of managerial decisions. The choice of management decisions on the development of industrial enterprises on the basis of energy saving, which are determined by building a cognitive model, is substantiated. According to the results of the analysis, the influence of sixteen factors of the external business environment on the formation of adherent solutions for the management of industrial development based on pulse modeling is studied. It is proved that, in the system of innovative management of industrial enterprises development, the target factor is the "Level of enterprise development", and other studied factors are controlled. The use of dynamic analysis makes it possible to identify stabilizing and destabilizing factors influencing the development of industrial enterprises. The ranges of change of factors-indicators of industrial enterprises development management in the system "minimummaximum" are defined. In conclusion, on the basis of the constructed cognitive map of innovative management of the development of electricpower industry enterprises, the ranges of change of factors-indicators of enterprise development management are determined.
\end{abstract}

Keywords. innovation, cognitive-linguistic analysis, monitoring, enterprise development, industrial enterprises.

\section{Introduction}

There is no doubt that the sustainable socio-economic development of any country depends largely on the growth of energy efficiency of the national economy [1].

\footnotetext{
*Corresponding author: svetlana.drobyazko@yahoo.com
} 
Energy saving is the most important factor in improving energy efficiency, economic efficiency, and economic security of business [2].

Issues of energy saving due to rising energy prices, shortages, the need to import energy resources, and their irrational consumption remain in the spotlight at the present stage of development of society. The negative factor is the high energy intensity of the Ukrainian economic system. This is especially true of industries such as metallurgy, chemical industry, coal mining, and so on. Energy consumption of industrial companies does not meet the conditions of an energy efficient society [3].

High costs of fuel and energy resources limit the competitiveness of national production, in particular in conditions of external energy dependence. A significant part of energy consumption does not allow companies to obtain the necessary values of profit, slows down development. As a result, the high share of fuel and energy costs in the production costs of companies does not increase the competitiveness of national products.

Fuel and energy resources of own production are not enough to meet the needs of industry and households in Ukraine, which requires the import of energy at a fairly high price. Assessing the prospects for energy development in Ukraine, it should be noted that for sustainable development it is advisable to introduce renewable energy sources as an alternative to outdated resource-intensive technologies [4].

Due to the depletion of non-renewable energy sources, their high cost and low efficiency in use, the harmful effects on the environment in the world are increasingly used by alternative and renewable energy sources. In recent years, there has been a tendency in Ukraine to increase the share of energy supply from renewable sources [5].

One of the modern approaches to analyzing and solving complex problems of innovative management of enterprise development is the use the cognitive modeling as a method of providing determining the strength and direction of factors` influence on the transfer of the management object at a particular target state taking into account the similarities and differences in the effects of various factors on the object [6-9].

The purpose of this work is to build a cognitive model of enterprise development based on energy saving.

\section{Method}

One of the well-known approaches to solving the problems of dynamic systems management is cognitive modeling, which methodology is designed to analyze and use the solutions obtained for poorly formalized situations [10,11].

Cognitive analysis is considered as one of the most powerful tools for studying an unstable and poorly structured environment.

It contributes to a better understanding of the problems existing in the environment, identification of contradictions and qualitative analysis of the processes taking place [12].

The goal of cognitive modeling is to generate and test hypotheses regarding the functional structure of the observed situation until a functional structure is available that can explain the behavior of the observed situation.

The cognitive approach to decision-making support is focused on activating the intellectual processes of the enterprise and helping it to fix the presentation of the problem situation in the form of a formal model [13].

The cognitive map of the situation is usually used as such a model, which provides the subject with the basic laws and patterns of the observed situation in the form of an oriented sign graph in which the peaks of the oriented sign graph are factors (signs, characteristics of the situation), and the arcs between factors are cause and effect relations between factors $[14,15]$.

There are several significant characteristics of cognitive modeling. 
One of the most effective vectors of innovative development management in the face of uncertainty is the creation of the so-called "intellectual socio-economic system", that is, a system capable of self-improvement, self-learning and continuous innovative development [16]. As a result, enterprises need to develop a system that seeks not only to adapt to changes in the internal environment, but also actively works towards creating the most profitable external environment.

Cognitive processes aim to lead to positive innovative transformations in the activities of enterprises, the active involvement of intellectual and socio-economic components.

Cognitive analysis and modeling are fundamentally innovative elements in the structure of the system of production of effective management decisions and they allow [17]: explore issues with fuzzy factors and relationships; take into account the impact of environmental changes; to use objective tendencies of innovative development of a situation in their interests.

The prerogative of the cognitive modeling method is that it can operate not only with exact quantitative values and formulas, but also with qualitative values and estimates. The essence of cognitive modeling is that formal mathematical methods of analysis are applied to models that describe the subjective vision of a situation [18].

At each stage of the model formation, decisions have to be made, on the sum of which the adequacy of the constructed model depends. The cognitive approach to decision support is oriented towards activating the intellectual processes of the subject and helping him to fix his vision of the problem situation in the form of a formal model.

In the cognitive model, two types of causal relationships are distinguished: positive and negative. With a positive relationship, an increase in the value of the factor-cause leads to an increase in the value of the factor-effect, and with the negative it leads to its decrease.

A qualitative analysis of the cognitive model (the content of its constituent blocks, target and control factors, the analysis of ways and cycles, cause-effect relationships and their nature) does not reveal the full depth of phenomena and processes taking place in a real system $[19,20]$.

Therefore, the next stage of the study is the modeling of the impulse process of spreading the disturbances, that is the transition of a system from one state to another either evolutionarily, or under the influence of management factors or disturbing influences. Each such impulse process is a possible scenario for the development of the system.

This method of studying the dynamics of processes is simpler than an analytical study of behavior models in the form of systems of differential equations which are difficult to construct for social, economic, environmental, etc. objects. In addition, impulse modeling on cognitive maps, which is an "external" description of systems, allows one to study the tendencies of dynamic changes for the entire system as a whole.

\section{Results and discussion}

In a market economy, innovative management is a decisive tool for competition, which provides the conditions for stable long-term development of enterprises [21]. Innovative enterprise development management largely determines the economic development of the regions and the country as a whole, increases employment and increases productivity, and is an important factor in socio-economic development [22].

The purpose and task of managing enterprise development is to achieve changes in the states of systems in some desirable direction, and the object of management is the area of the problem, which is considered as a dynamic situation, composed of many heterogeneous (interacting directly or indirectly) factors.

However, in general, the situations studied are poorly structured. Signs of weak structure include: lack of certainty of factors and relationships there between, changes in 
system parameters that can lead to significant changes in its structure, which are difficult to predict, the presence of qualitative values of factors or the degree of their influence, possible fuzzy representations, linguistic estimates forming a linearly ordered scale, values of the parameters of the situation are obtained according to experts, therefore they are their subjective assessments.

Economic systems operating in poorly structured situations evolve over time, and they are characterized by the possibility of the disappearance of part of the relationships or factors, changes in the strength of the relationships. The identity of such systems is confirmed only evolutionarily (as they passed from one state to another).

An example of such systems are regional or sectoral models of various socio-economic systems, models that arise in the calculation of business plans, and other models that go beyond the field of relevance (the range within which a fixed model of cost behavior is maintained). The basis of the cognitive modeling method is the use of the cognitive map (the cognitive map of the situation acts as a formal model).

The complexity of analyzing the processes of innovative management of enterprise development is due to a number of features typical for this direction, namely: the multidirectional processes of activities carried out and establishing interconnections, due to which it is impossible to isolate and thoroughly study the individual phenomena that should be considered as a whole; the lack of sufficient quantitative information on the dynamics of processes, which forces us to move on to a qualitative analysis of these processes; the variability of the nature of processes over time and the like.

The basis of the cognitive modeling method is the use of the cognitive map (the cognitive situation map is the formal model).

The cognitive model is an oriented sign graph, in which positive lines between factors are indicated by continuous lines, and negative ones are indicated by dotted lines (Figure $1)$.

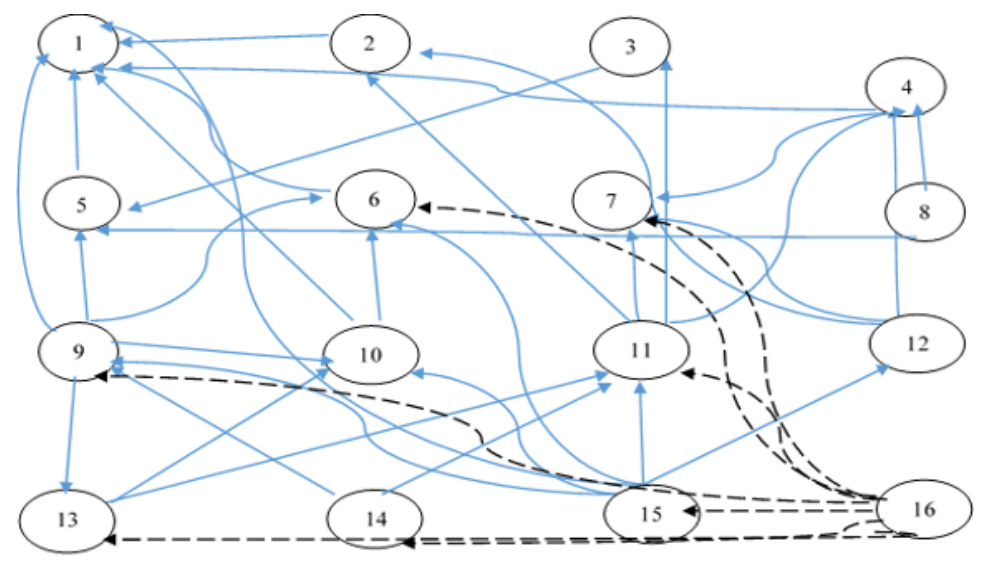

Fig. 1. The cognitive map of innovative management of the development of enterprises in the electric-power industry.

Graph nodes: 1 - number of industrial enterprises; 2 - the level of service of enterprises;

3 - the number of employees in enterprises; 4 - infrastructure development; 5 - the level of development of the energy market; 6 - the number of customers served; 7 - the number of transmission downtime; 8 - the number of devices of alternative energy sources; 9 - investment activities; 10 - financing of industrial enterprises at the expense of the state budget; 11 - living standards; 12 - stability of the political situation in the country; 13 -total technological capacity of renewable energy sources; 14 - natural and geographical resources; 15 - ecological condition in the country; 16 - anthropogenic load. 
In the constructed model, the target factor is the "Level of Enterprise Development", and the other factors studied are manageable. The study of the constructed cognitive model by the methods of static and dynamic analysis shows stabilizing and destabilizing factors of influence on the development of enterprises.

The cognitive map of enterprise development management testifies to the dependence of factors that positively or negatively affect the development of these enterprises, namely: positive impact of additional investments, effective measures of financial support at the state level, stability of the political situation, infrastructure development, natural and geographical resources, ecological status in the country. These factors will have a positive impact not only on the development of enterprises, but also on raising the level of industry, which will increase the level of attractiveness of the country and attract additional financial revenues to the country's budget.

The relationship between the factors is given in the form of a matrix of contiguity of factors (Table 1), in which the sign " +1 " indicates a positive relationship between the nodes, the sign "-1" - a negative relationship, the sign " 0 " - no significant connection.

Table 1. Matrix of contiguity of factors.

\begin{tabular}{|r|r|r|r|r|r|r|r|r|r|r|r|r|r|r|r|r|}
\hline № & 1 & 2 & 3 & 4 & 5 & 6 & 7 & 8 & 9 & 10 & 11 & 12 & 13 & 14 & 15 & 16 \\
\hline 1 & 0 & 0 & +1 & +1 & 0 & 0 & 0 & 0 & 0 & 0 & 0 & 0 & 0 & 0 & 0 & 0 \\
\hline 2 & +1 & 0 & 0 & 0 & +1 & +1 & 0 & 0 & 0 & 0 & 0 & 0 & 0 & 0 & 0 & 0 \\
\hline 3 & 0 & 0 & 0 & 0 & 0 & 0 & 0 & 0 & 0 & 0 & 0 & 0 & 0 & 0 & 0 & 0 \\
\hline 4 & 0 & +1 & 0 & 0 & +1 & +1 & +1 & 0 & 0 & 0 & 0 & 0 & 0 & 0 & 0 & 0 \\
\hline 5 & +1 & 0 & 0 & 0 & 0 & 0 & 0 & 0 & 0 & 0 & 0 & 0 & 0 & 0 & 0 & 0 \\
\hline 6 & +1 & 0 & 0 & 0 & 0 & 0 & 0 & 0 & 0 & 0 & 0 & 0 & 0 & 0 & 0 & 0 \\
\hline 7 & +1 & 0 & 0 & 0 & 0 & 0 & 0 & 0 & 0 & 0 & 0 & 0 & 0 & 0 & 0 & 0 \\
\hline 8 & +1 & 0 & +1 & +1 & +1 & +1 & 0 & 0 & 0 & 0 & 0 & 0 & 0 & 0 & 0 & 0 \\
\hline 9 & +1 & 0 & +1 & 0 & +1 & +1 & +1 & 0 & 0 & 0 & 0 & 0 & 0 & 0 & 0 & 0 \\
\hline 10 & +1 & 0 & 0 & 0 & 0 & +1 & 0 & 0 & 0 & 0 & 0 & 0 & 0 & 0 & 0 & 0 \\
\hline 11 & +1 & +1 & +1 & +1 & 0 & 0 & +1 & 0 & 0 & 0 & 0 & 0 & 0 & 0 & 0 & 0 \\
\hline 12 & +1 & 0 & 0 & +1 & 0 & +1 & +1 & 0 & 0 & 0 & 0 & 0 & 0 & 0 & 0 & 0 \\
\hline 13 & 0 & 0 & 0 & 0 & 0 & +1 & 0 & 0 & 0 & +1 & +1 & 0 & 0 & 0 & 0 & 0 \\
\hline 14 & 0 & 0 & 0 & 0 & 0 & +1 & 0 & 0 & +1 & +1 & +1 & 0 & 0 & 0 & 0 & 0 \\
\hline 15 & +1 & 0 & 0 & 0 & 0 & +1 & 0 & 0 & +1 & +1 & +1 & +1 & 0 & 0 & 0 & 0 \\
\hline 16 & -1 & 0 & 0 & 0 & 0 & -1 & -1 & 0 & -1 & 0 & -1 & 0 & -1 & -1 & -1 & 0 \\
\hline
\end{tabular}

The adjacency matrix is not symmetric, as the factors do not necessarily have to be interrelated.

So, cognitive modeling combines two types of modeling - structural-systemic and simulation, which allows the most fully and adequately reflect the real object and build mathematical models, the results of which are easy to interpret in practice.

Static analysis of the cognitive model of intersectoral interaction in the field of enterprise development allowed to identify the factors that contribute to or impede the development. The results of the analysis of the system characteristics of the cognitive model revealed that special attention in intersectoral interaction should be paid to the interaction of two sectors: enterprises and power business. 
Dynamic analysis has allowed to generate alternative scenarios of innovative management of enterprise development depending on the influence of various factors. Thus, it can be concluded that an increase in investments in power business activities will increase the level of market development by one period earlier than the increase in budget financing.

Taking into account the results of the conducted researches, a cognitive map of innovative management of enterprise development is drawn up, which shows connections that are positive and negative.

Similarly, we define the ranges of factors-indicators of enterprise development management, that is, by integrated assessments and the overall assessment of integrated management of enterprise development (Table 2).

Table 2. The range of change of factors-indicators of enterprise development management.

\begin{tabular}{lccr}
\hline Factor-indicator & Abbreviations & $\begin{array}{l}\text { min } \\
\text { value }\end{array}$ & $\begin{array}{l}\text { max } \\
\text { value }\end{array}$ \\
\hline Innovative component of the enterprise & F1 & 0,012 & 0,546 \\
\hline Decision making component of the enterprise & F2 & 0,042 & 0,753 \\
\hline $\begin{array}{l}\text { The component of reflection of the final results of the } \\
\text { enterprise }\end{array}$ & F3 & 0,057 & 0,359 \\
\hline An integral part of revealing the opinions of the company staff & F4 & 0,088 & 0,777 \\
\hline Marketing component of the enterprise & F5 & 0,018 & 0,17 \\
\hline Component of enterprise development & F6 & 0,062 & 0,673 \\
\hline Management component of the enterprise & F7 & 0,266 & 0,964 \\
\hline The component of economic research of the enterprise & F8 & 0,238 & 1,318 \\
\hline Personnel component of the enterprise & F9 & 0,324 & 1,374 \\
\hline Risk occurrence and assessment of the enterprise & F10 & 0,074 & 0,726 \\
\hline Optimization of enterprise costs & F11 & 0,106 & 0,903 \\
\hline
\end{tabular}

Dynamic analysis allowed to generate alternative scenarios of innovative management of enterprise development depending on the influence of various factors. Thus, we can conclude that increasing investment in the energy business will increase the level of market development by one period earlier than increasing funding from the budget.

Based on the results of research, a cognitive map of innovative management of industrial development, which shows the links between positive and negative.

Similarly, we define the ranges of parameters-indicators of enterprise development management, ie by the integrated assessments and the general assessment of integrated enterprise development management (Figures 2-3).

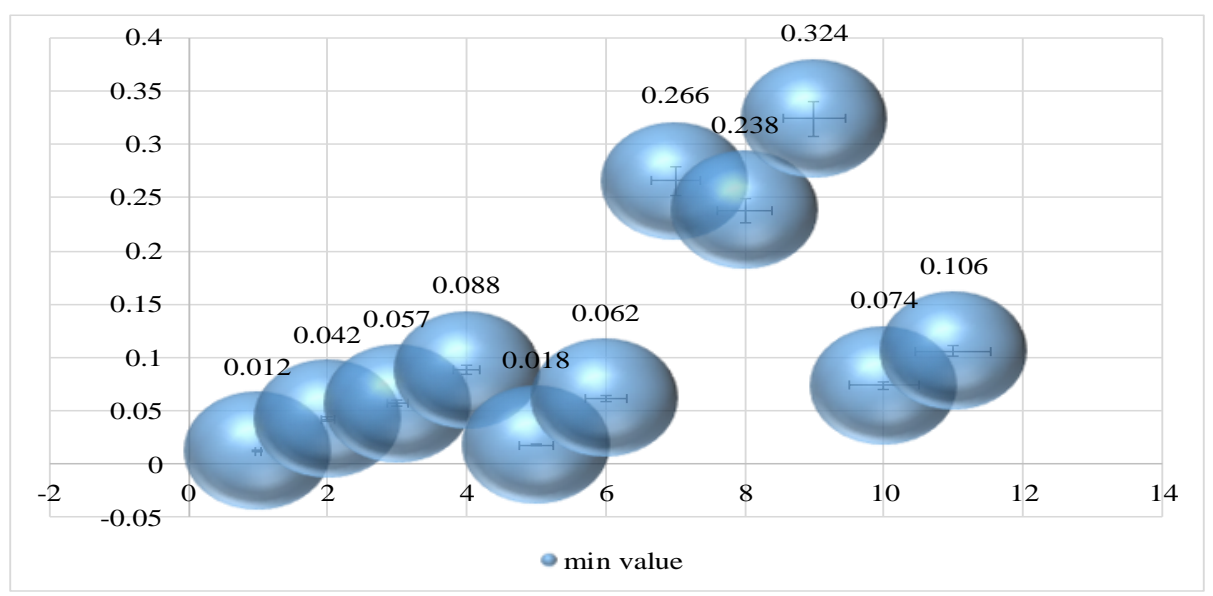


Fig. 2. Ranges of change of factors-indicators of the industrial enterprises development management (minimum value).

Using the rules of correspondence between factors-causes and factors-effects, the qualitative dependencies of the cognitive model are determined.

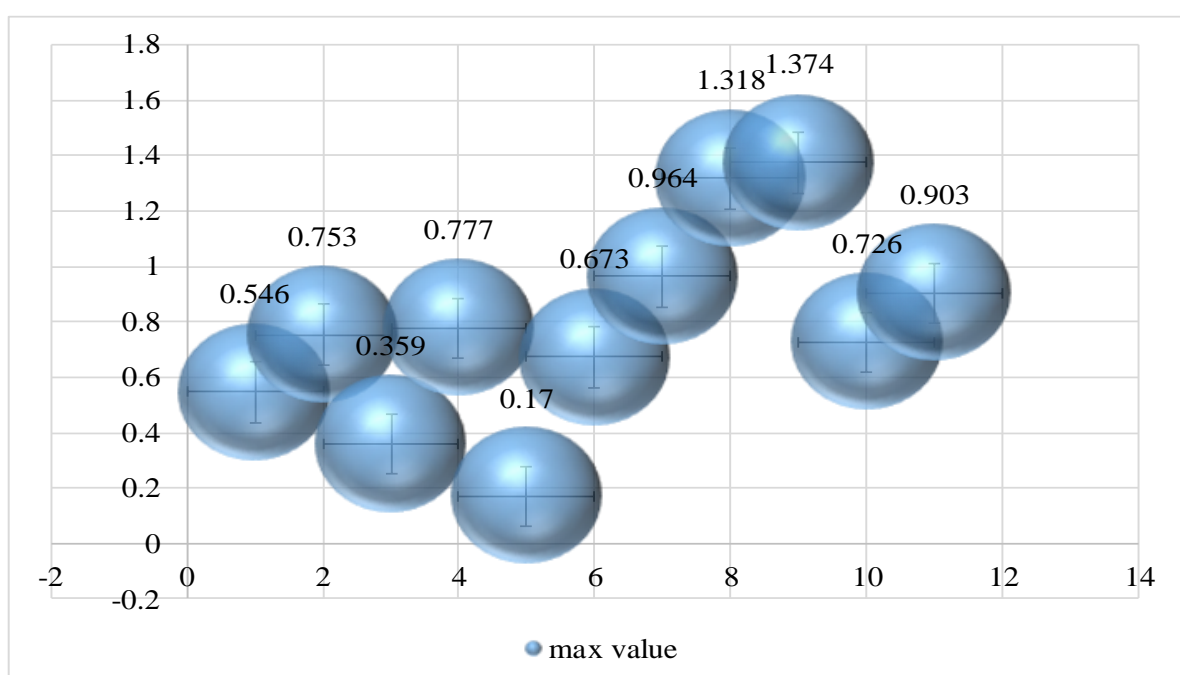

Fig. 3. Ranges of change of factors-indicators of the industrial enterprises development management (maximum value).

So, in the formation of the reference model, the uncertainty is manifested in the insufficient completeness of information on the parameters of the width of the range of services provided by the enterprise, the quality of their provision, as well as the socioeconomic situation in the regions of the country and the ares of their influence. At the same time, there is a chance of making mistakes when collecting the source data (Figure 4).

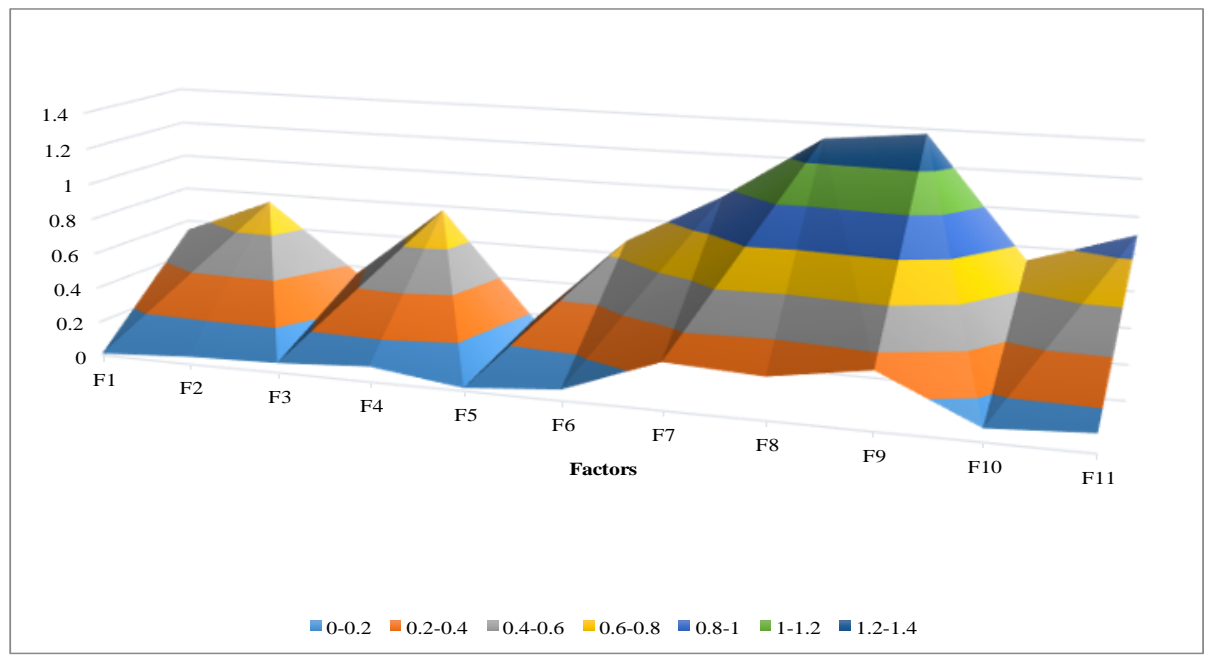

Fig. 4. Graphical interpretation of ranges of change of factors-indicators of the power branch enterprises development 
Uncertainties in modeling the perspective state of enterprises arise in the process of finding the optimal combination of design measures for the most effective solution of the problems of the industry development.

According to the results of the cognitive analysis conducted, enterprises have the opportunity to receive new attractors of innovative development, the use of which will allow to evaluate the existing environment and adapt or change in accordance with its requirements at the lowest cost.

So, cognitiveness can be used as one of the directions of regulating the activity of enterprises, expresses the specifics of the means of displaying and modeling their innovative development management that implement it. Cognitiveness affects selfregulation processes of goal formation and the feasibility of innovative management of enterprise development, the formation of activity models and determining the format of executive actions in order to achieve effective results.

The basis for the development of enterprises is the scientifically-practically-based innovative management that helps eliminate obsolete, uncompetitive forms of management, the formation and implementation of new creative forms that are more consistent with the acceleration of scientific and technological progress, adapted to the objective requirements of modern society.

The transition to innovative management of enterprise development makes it possible to use the available economic resources and advantages that contribute to competitiveness.

When developing and implementing innovative management of enterprise development, it is important to consider: objective changes in the world, as well as the interests of individual partner countries with foreign economic relations; relations with domestic and foreign enterprises; own competitive advantages and competitive advantages of leading enterprises.

Innovative management of enterprise development should contain tools for adapting to the conditions of liberalization and globalization of the global economy, incentives for cooperation with domestic and foreign partners, the effective use of their innovative competitive advantages, and the like.

So, the basis for the formation of an integrated mechanism for innovative management of enterprise development is a system that determines the interconnections and interdependence between the components of support, the stages of solving problems and the mechanisms of formation of innovative activity in the enterprise development management system with the aim of organizing the implementation of management functions and the effectiveness of innovative management of enterprise development in modern permanent functioning conditions.

\section{Conclusion}

Features of construction of cognitive model of industrial enterprises development on the basis of energy saving are considered. The stages of implementation of cognitive modeling of industrial enterprise development management are determined. Cognitive analysis and modeling are fundamentally innovative elements in the structure of the system of producing effective management decisions and allows: to explore problems with fuzzy factors and relationships; to take into account the impact of changes in the external environment; to use objective tendencies of innovative development of a situation in the interests. These technologies are gaining more and more trust in the structures engaged in strategic and operational planning at all levels and in all areas of innovative management of industrial development. 
The use of cognitive technologies in the economic sphere allows in a short time to develop and justify a strategy of innovative management of industrial development, taking into account the impact of changes in the internal and external environment.

The factors of the cognitive model of innovative management of industrial enterprises development on the basis of four sectors are considered: industrial enterprises; energy business; power; ecology. The influence of 16 factors of the external business environment on the formation of adjectival management solutions for the development of industrial enterprises based on pulse modeling has been studied. It is proved that in the system of innovative management of industrial enterprises development the target factor is the "Level of enterprise development", and other studied factors are controlled.

The use of dynamic analysis allows to determine the stabilizing and destabilizing factors influencing the development of industrial enterprises. The ranges of change of factors-indicators of the industrial enterprises development management in the system "minimum-maximum" are defined.

\section{References}

1. R. Albuquerque, Y. Koskinen, and C. Zhang, Manage. Sci. 65, 4451 (2019)

2. R. M. Anderson, H. Heesterbeek, D. Klinkenberg, and T. D. Hollingsworth, Lancet 395, 931 (2020)

3. S. Drobyazko, O. Bondarevska, D. Klymenko, S. Pletenetska, and O. Pylypenko, J. Manag. Inf. Decis. Sci. 22, (2019)

4. H. He and L. Harris, J. Bus. Res. 116, 176 (2020)

5. T. Kurbatova and H. Khlyap, Renew. Sustain. Energy Rev. 52, 217 (2015)

6. J. Cao, H. Liang, and X. Zhan, Manage. Sci. mnsc. 2018.3100 (2019)

7. E. Chen, G. Zhang, and T. Fu, in Proc. 2015 Int. Conf. Econ. Manag. Law Educ. (Atlantis Press, Paris, France, 2015)

8. J. Cui, H. Jo, and H. Na, J. Bus. Ethics 148, 549 (2018)

9. S. Drobyazko, A. Barwińska-Małajowicz, B. Ślusarczyk, L. Zavidna, and M. Danylovych-Kropyvnytska, J. Entrep. Educ. 22, (2019)

10. A. Durmanov, V. Bartosova, S. Drobyazko, O. Melnyk, and V. Fillipov, Entrep. Sustain. Issues 7, 1377 (2019)

11. A. Dyck, K. V. Lins, L. Roth, and H. F. Wagner, J. Financ. Econ. 131, 693 (2019)

12. J. W. Goodell, Financ. Res. Lett. 35, 101512 (2020)

13. Z. H. A. N. G. Guaili, Y. A. N. Jun, and A. I. B. Guangdong, Nat. Resour. Econ. China 6, (2017)

14. T. Hilorme, I. Perevozova, A. Sakun, O. Reznik, and Y. Khaustova, Acad. Account. Financ. Stud. J. 24, (2020)

15. T. Hilorme, K. Tkach, O. Dorenskyi, O. Katerna, and A. Durmanov, J. Manag. Inf. Decis. Sci. 22, (2019)

16. D. Jamali and C. Karam, Int. J. Manag. Rev. 20, 32 (2018)

17. A. Kıymalığlu, Impact of Digital Transformations on Corporate Social Responsibility (CSR) Practices in Turkey: A Study of the Current Environment (IGI Global, Pennsylvania, 2020)

18. A. Kleine and M. von Hauff, J. Bus. Ethics 85, 517 (2009)

19. L. M. Koonin, J. Bus. Contin. Emer. Plan. 13, (2020)

20. T. Laing, Extr. Ind. Soc. 7, 580 (2020)

21. S. Chowdhury, J. Contemp. Gov. Public Policy 1, 53 (2020)

22. J. Wu, Y. Guo, and J. Zhou, Water 12, 663 (2020) 